\title{
SIMULATION OF ROOM CLIMATE OF PUBLIC BUILDINGS
}

\author{
Maria Prorokova ${ }^{1, *}$, and Vyacheslav Bukhmirov ${ }^{1}$ \\ ${ }^{1}$ State Educational Institution of Higher Professional Education Ivanovo State Power University \\ named after V.I. Lenin, 1153003 Ivanovo, Russia
}

\begin{abstract}
The article presents the details of modeling of heat exchange and mass transfer in a room in the formation of a microclimate. The mathematical model is implemented in the program ANSYS Fluent and is used to predict the climate parameters after the implementation of energy saving measures in the building. Verification of the mathematical model by comparing the experimental data with the results of the measurement of microclimate parameters of the experiment.
\end{abstract}

\section{Introduction}

In $[1,2,3]$ shows that in the assessment of the effectiveness of energy-saving measures for non-production buildings (residential, public and administrative), an important task is to predict climate parameters that determine the comfort of the premises after the implementation of energy saving measures. Currently, scientists are actively used by a number of software and computer systems, allowing defining the parameters of the environment in the room after making changes to the technical characteristics of the building or changing the operating mode of the power equipment. The most common software and computing systems in the field of modeling of heat and mass transfer processes in the formation of microclimate buildings include Ansys Fluent, STAR-CD, FlowVision, GasDynamicsTool (GDT), SimuLink.

In order to modeling of convective and radiative heat transfer in the formation of room climate using a distributed model (fully or partially) and lumped parameters. Models with distributed parameters include the continuity equation, motion, heat balance, the balance of impurities in the form of differential partial recorded for air as a viscous compressible fluid $[4,5]$.

\section{Mathematical model}

In the Ivanovo Power Engineering University (ISPU), has developed a mathematical model that describes the movement processes, heat and mass transfer on the assumption that the air in the rooms for a stay of people is a three-component mixture of gases (air directly, carbon dioxide and water vapor). In this case, the mathematical modeling of the formation

\footnotetext{
* Corresponding author: prorokova mv@list.ru
} 
of a microclimate is based on the continuity equation for a mixture of gases, transfer of momentum equation and the equation of conservation of energy $[6,7,8]$.

In the equations of the mathematical model, the following assumptions:

1) in the equation of energy conservation compressibility accounted only the main component of the mixture - the air, since the concentration of carbon dioxide and water vapor in the gas mixture are small;

2) in the gas mixture is not diathermancy indoor environment;

3 ) the air flow is carried out uniformly over the entire surface of the air-permeable element enclosing structure room.

The mathematical model of indoor climate averaged parameters used gas mixture, in particular:

- the density of the gas mixture, $\mathrm{kg} / \mathrm{m}^{3}$ :

$$
\rho_{m}=\gamma_{f} \rho_{f}+\gamma_{\mathrm{CO}_{2}} \rho_{\mathrm{CO}_{2}}+\gamma_{\mathrm{H}_{2} \mathrm{O}} \rho_{\mathrm{H}_{2} \mathrm{O}}
$$

- dynamic viscosity mixture, Pa·s:

$$
\mu_{m}=\gamma_{f} \mu_{f}+\gamma_{\mathrm{CO}_{2}} \mu_{\mathrm{CO}_{2}}+\gamma_{\mathrm{H}_{2} \mathrm{O}} \mu_{\mathrm{H}_{2} \mathrm{O}}
$$

where $\gamma_{i}$ - bulk concentration of the $i$-th component of the mixture, $\mathrm{m}^{3} / \mathrm{m}^{3} ; \rho_{i}$ - density of $i$ th component of the mixture, $\mathrm{kg} / \mathrm{m}^{3} ; \mu_{\mathrm{i}}$ - viscosity component of the mixture, $\mathrm{Pa} \cdot \mathrm{s}$. Indexes $\mathrm{f}, \mathrm{CO}_{2}, \mathrm{H}_{2} \mathrm{O}$, respectively designated air, carbon dioxide and water vapor.

The mathematical model is different, first of all, to use when setting the boundary conditions of actual air space, which is determined experimentally [9]. Secondly research shows [12], the presence of heated or cooled surfaces in the room can have a significant impact on the human feeling of comfort, in accordance with this radiation heat transfer is taken into account by introducing a special source term in the energy equation $[4,5]$.

For a description turbulent properties of the gas mixture used $k-\varepsilon$ turbulence model $[10$, 11].

In [2] as an additional factor has been proposed level of climate comfort, which includes a coefficient comfort human thermal state $(\mathrm{CCH})$, which was determined by solving the heat of human balance, as well as amendments to the radiative cooling, the asymmetry of the heat flow and air quality medium (the presence of impurities) in the room. Check the adequacy of the developed mathematical model is executed by comparing the $\mathrm{CCH}$ values obtained from the experimental results and the implementation of a mathematical model in the environment of ANSYS Fluent. To do this in the classroom ISPU an experiment was conducted on the Measurement of microclimate parameters (temperature, relative humidity, air mobility), as well as the temperature of the enclosing surfaces and air spaces.

Further based on the results of the experiment coefficient of thermal comfort the human condition was calculated. And then in the software and computer system created a geometric model of experimental facilities and to implement the proposed mathematical model of heat transfer in this area. According to the simulation results of the determined value of the coefficient of thermal comfort the human condition. In the experiment, and the mathematical modeling of controlled and the average air temperature in the room.

\section{Results and discussion}

As a result of experimental and theoretical study of the microclimate in the educational university auditorium was obtained value of the coefficient of thermal comfort condition of the person according to the experiment -0.412 , and the results of the simulation - 0,329. The average air temperature in the test room according to the experiment was equal to - 
$26.2{ }^{\circ} \mathrm{C}$, and in the simulation results $-24.45{ }^{\circ} \mathrm{C}$. Comparison of experimental results and mathematical modeling indicates the adequacy of the developed mathematical models of indoor climate in terms of determining the coefficient of thermal comfort the human condition.

\section{Conclusions}

1. Was developed a mathematical model of heat and mass transfer processes in the the premises of human presence, which allows on the basis of information on the actual air exchange, predict indoor climate parameters.

2. The adequacy of the proposed mathematical model was verified by comparing the experimental and calculated values of human comfort factor of the thermal state and the average air temperature in the room classroom.

\section{References}

1. Y.A. Tabunschikov, AVOK 5 (2008)

2. V.V. Bukhmirov, M.V. Prorokova, Bulletin ISPU 4 (2015)

3. P.O. Fanger, AVOK 4 (2003)

4. L.D. Landau, E.M. Lifshitz, Continuum Mechanics: Hydrodynamics and elasticity theory (Dep. publ tehnikoteoret. lit., OGIZ, Moscow, 1944)

5. S. Patankar, Numerical methods for solving problems of heat transfer and fluid dynamics (Energoatomisdat, Moscow, 1984)

6. ANSYS FLUENT User's Guide. Software Release Version 14 (2011)

7. Y.A. Tabunschikov, M.A. Brodach, Mathematical modeling and optimization of thermal efficiency of buildings (AVOC-PRESS, Moscow, 2002)

8. A.Y. Snegirev High-performance computing in engineering physics. Numerical simulation of turbulent flows: Proc. allowance (Publishing house of the Polytechnic. University Press, St. Petersburg, 2009)

9. V.V. Bukhmirov, M.V. Prorokova, Herald of the Russian Ministry of Energy 1, 1 (2015)

10. I.A. Belov, S.A. Isaev, Simulation of turbulent flows: Proc. Allowance (Balt. state. tehn. University Press, St. Petersburg, 2001)

11. A.A. Yun, B.A. Krylov, Calculation and simulation of turbulent flows with heat exchange, mixing, chemical reactions, and two-phase flows in the software package FASTEST-3D (Publishing house of the Moscow Aviation Institute, Moscow, 2007)

12. A. Machkashi, L. Banhidi, Radiant heating (Stroyizdat, Moscow, 1985) 